\title{
Differential diagnoses in COVID-19 pandemic: a retrospective descriptive study
}

\author{
Elia Rigamonti, ${ }^{1}$ Tanja Fusi-Schmidhauser, ${ }^{1}$ Gianluca Argentieri, ${ }^{2}$ Pietro Gianella ${ }^{1,3}$ \\ ${ }^{1}$ Internal Medicine Department; ${ }^{2}$ Radiology Department; and ${ }^{3}$ Pneumology Department, Regional Hospital of Lugano, Can- \\ tonal Hospital Authority, Lugano, Switzerland
}

\begin{abstract}
Since February 2020, severe acute respiratory syndrome-related coronavirus 2 (SARS-CoV-2) infection rapidly spread across Southern Switzerland. The available literature on differential diagnoses of coronavirus 2019 (COVID-19) is scarce. Our study aims to review differential diagnoses of SARS-CoV-2 infections in public hospitals in Southern Switzerland and describe patients' related outcomes. Between 01.03.2020 and 15.04.2020, 344 patients had a chest computed tomography-scan at admission, 210 of them were pathological. 172 patients had a positive nasopharyngeal swab for SARS-CoV-2, and 38 patients needed an additional diagnostic work-up and were included in this study. Among the selected patients, 8 underwent 2 polymerase chain reaction (PCR) for SARS-CoV-2, while 18 patients were subjected to 3 PCR. We observed 29 infective cases, 3 due to cardiovascular etiologies, 2 due to chronic obstructive pulmonary disease exacerbation, 1 due to cryptogenic organizing pneumonia, 3 not related to respiratory diseases. Our results highlight the importance of differential diagnosis in times of widespread occurrence of COVID-19, considering the similarity of symptoms and imaging appearance with other respiratory conditions.
\end{abstract}

Correspondence: Elia Rigamonti, Internal Medicine Department, Regional Hospital of Lugano, Cantonal Hospital Authority, via Tesserete 46, 6900 Lugano, Switzerland. Tel.: +41.918117738.

E-mail: elia.rigamonti@eoc.ch

Key words: Interstitial bilateral pneumonia; differential diagnoses; COVID-19; SARS-CoV-2 infection.

Acknowledgments: we would like to thank Dr. Valerio Vitale for his technical support.

Contributions: ER and PG conceived the presented idea of the study; ER wrote the manuscript with support from TF-S and PG; GA contributed to figure preparation; TF-S supervised the project. All authors read and approved the final version of the manuscript.

Conflict of interests: the authors declare no potential conflict of interests.

Availability of data and materials: they are extracted from patients' hospital charts, and conserved in anomysed and securised form.

Ethics approval and consent to participate: the Institutional Ethics Committee of Southern Switzerland approved this study as a diagnostic quality review project. Written informed consent was obtained from the patients for their anonymized information to be published in this article.

Received for publication: 26 October 2020.

Revision received: 24 November 2020.

Accepted for publication: 23 December 2020.

This work is licensed under a Creative Commons Attribution NonCommercial 4.0 License (CC BY-NC 4.0).

${ }^{\circ}$ Copyright: the Author(s), 2021

Licensee PAGEPress, Italy

Italian Journal of Medicine 2021; 15:48-52

doi:10.4081/itjm.2020.1410

\section{Introduction}

Since February 2020, the severe acute respiratory syndrome-related coronavirus 2 (SARS-CoV2) infection rapidly spread throughout Switzerland, with a peak in confirmed cases between March 23 and 27, 2020. ${ }^{1,2}$ Southern Switzerland represented an epicenter for coronavirus 2019 (COVID-19) disease during this period, with 3327 reported cases, 350 fatalities, and a cumulative prevalence of 94.2/10,000 cases at the end of June 2020. ${ }^{3}$ Even in times of pandemic, it is of utmost importance to consider other differential diagnoses since timely diagnosis and appropriate management may affect the outcome. During the 2009 influenza A (H1N1) pandemic, many bacterial co-infections and secondary infections occurred, resulting in substantial morbidity and mortality. ${ }^{4}$ Misdiagnosis was also a concern due to availability bias, and treatable bacterial, viral, or parasitic infections were mistakenly labeled as influenza A infections. ${ }^{5}$

The available literature on differential diagnoses of SARS-CoV-2 infection is scarce. Single case reports or series on infectious or non-infectious differential diagnoses, such as pulmonary contusion, opportunistic infections, heart failure, and drug-induced pneumonitis, have been published. ${ }^{3,6-9}$ Furthermore, several papers were published in the early phases of the pandemics, where the epidemiological situation was different. ${ }^{10,11}$ Our study aims to review differential diagnoses of SARS-CoV-2 infections in public hospitals in Southern Switzerland and describe patients' related outcomes. 


\section{Materials and Methods}

Retrospective, descriptive study of patients who underwent a chest computed tomography (CT)-scan with a pathological result and were admitted to all Cantonal Hospital Authorities (Ente Ospedaliero Cantonale, EOC) hospitals in Southern Switzerland between March 1 and April 15, 2020. Patients with suspicion of SARS-CoV-2 infection and at least one negative real-time polymerase chain reaction (RTPCR) for SARS-CoV-2 in nasopharyngeal specimens were included in the study. The case definition for SARS-CoV-2 suspicion was defined by the institution as follows: symptoms of acute respiratory disease, and/or fever without other explanations, and/or sudden loss of sense of taste and/or smell, and/or acute delirium in the elderly or history of close contact with a confirmed COVID-19 case (at least 15 minutes at a distance $<1.5$ meters).

All clinical records of these patients were then reviewed while evaluating the diagnostic workup necessary to establish a definite diagnosis. Demographic, clinical, and laboratory data were coded and collected on a duly created spreadsheet. Particular attention was paid to collecting and detailing all microbiological specimens (urines, feces, induced sputum, bronchoalveolar lavage, and serologies) in patients with negative RT-PCR for SARS-CoV-2 in nasopharyngeal specimens, but with a pathological CT-scan, in order to identify all patients with a COVID-19 disease.

Finally, we outlined the differential diagnoses that have been established by clinicians in charge of these patients. The ethics committee of Southern Switzerland approved the study as a diagnostic quality review project.

\section{Results}

A total of 344 patients had a chest CT-scan at admission, and in 210 chest CT-scans, pathological findings were described. 172 patients had a positive nasopharyngeal swab for SARS-CoV-2, and 38 patients needed an additional diagnostic work-up and were included in this study. Among the selected patients, 18 were males, and 20 females, the average age of all included patients was 66 years. 8 patients underwent 2 PCR for SARS-CoV2 , and 18 underwent 3 PCR. Among the 84 body fluids/specimens searched: in 50 cases, it was used nasopharyngeal swab, 16 PCR in induced sputum, 10 PCR in urines and feces, 6 in bronchoalveolar lavage, and finally 2 serologies. An overview of all demographic data is available in Table 1.

The majority of the alternative diagnoses to COVID-19 were infectious, with a predominance of bacterial pneumonia (22 patients, $57.9 \%$ of all cases), as depicted in Table 1. Other identified differential diagnoses included respiratory involvement conditions, such as pulmonary embolism, acute heart failure, and non-infectious COPD exacerbation. In 3 patients, the established diagnosis was not respiratory-related (Table 1). The calculated mortality rate during the hospital stay in all included patients was $10.8 \%$. Among the discharged patients, $71.4 \%$ could regain their home, while $28.6 \%$ were transferred to another hospital or rehabilitation clinic.

The following description of two clinical cases il-

Table 1. Demographics and microbiologic specimens of included patients.

\begin{tabular}{|c|c|}
\hline \multicolumn{2}{|l|}{ Demographics specimens } \\
\hline $\begin{array}{l}\text { Patients } \\
\text { Female (\%) } \\
\text { Mean age (SD) }\end{array}$ & $\begin{array}{c}38 \\
20(52.6) \\
66.0(16.6)\end{array}$ \\
\hline $\begin{array}{l}\text { Number of SARS-CoV-2 RT-PCR } \\
\text { One RT-PCR } \\
\text { Two RT-PCR } \\
\text { Three RT-PCR }\end{array}$ & $\begin{array}{c}11(28.9 \%) \\
8(21.1 \%) \\
19(50.0 \%)\end{array}$ \\
\hline $\begin{array}{l}\text { Other specimens } \\
\text { Induced sputum } \\
\text { Urines/feces } \\
\text { Bronchoalveolar lavage } \\
\text { gM/IgG serology }\end{array}$ & $\begin{array}{c}16(19.0 \%) \\
10(11.9 \%) \\
6(7.2 \%) \\
2(2.4)\end{array}$ \\
\hline Established diagnosis & \\
\hline Infectious & $29(76.3 \%)$ \\
\hline $\begin{array}{l}\text { Bacterial pneumonia } \\
\text { Community-acquired }=10 \\
\text { Streptococcus pneumoniae }=5 \\
\text { Ab ingestis pneumonia }=3 \\
\text { Hemophilus influenzae }=1 \\
\text { Pseudomonas aeruginosa }=1 \\
\text { Mycoplasma pneumoniae }=1 \\
\text { Legionella pneumophila }=1\end{array}$ & $22(57.9 \%)$ \\
\hline $\begin{array}{l}\text { Viral pneumonia } \\
\text { Community-acquired }=3 \\
\text { Adenovirus }=1 \\
\text { Human coronavirus OC43 }=1\end{array}$ & $5(13.2 \%)$ \\
\hline $\begin{array}{l}\text { Fungal infection } \\
\text { Pneumocystis jirovecii }=1\end{array}$ & $1(2.6 \%)$ \\
\hline $\begin{array}{l}\text { Bacterial and viral coinfection } \\
\text { Hemophilus influenzae } \text { and Adenovirus }=1\end{array}$ & $1(2.6 \%)$ \\
\hline Non-infectious & $9(23.7 \%)$ \\
\hline $\begin{array}{l}\text { Cardiovascular } \\
\text { Pulmonary embolism =2 } \\
\text { Acute heart failure }=1\end{array}$ & $3(7.9 \%)$ \\
\hline $\begin{array}{l}\text { COPD exacerbation } \\
\text { Cryptogenic organizing pneumonia }\end{array}$ & $\begin{array}{l}2(5.3 \%) \\
1(2.6 \%)\end{array}$ \\
\hline $\begin{array}{l}\text { Other } \\
\text { Prosthesis-related infection }=1 \\
\text { Left lower limb ischemia }=1 \\
\text { Ischemic cerebral stroke }=1\end{array}$ & $3(7.9 \%)$ \\
\hline
\end{tabular}


lustrates the challenges related to a timely and appropriate diagnosis and prompt treatment initiation during the COVID-19 pandemic in Southern Switzerland.

\section{Case \#1 - Bacterial infection due to Pseudomonas aeruginosa}

A 68-year-old woman was admitted to the emergency room for dyspnea and productive cough. Her past medical history was remarkable for COPD stage 4D, severe malnutrition, anxiety-depression syndrome with opioid consumption, and previous cutaneous Pseudomonas aeruginosa infections resistant to carbapenems. The clinical examination showed an afebrile patient with low oxygen saturation at $86 \%$ in room air, and the lung auscultation revealed diffuse wheezes.

The electrocardiogram (ECG) was normal, and the chest X-ray showed a bilateral accentuation of the lung parenchyma with small infiltration areas in the lower left lobe. The laboratory exams highlighted a substantial increase in inflammatory markers (C-reactive protein $178 \mathrm{mg} / \mathrm{L}$ ), moderate lymphocytopenia $(1.04 \times 10 \mathrm{E} 9 / \mathrm{L})$, and a moderate increase in hepatic enzymes (L-aspartate aminotransferase $50 \mathrm{U} / \mathrm{L}$, L-alanine aminotransferase $71 \mathrm{U} / \mathrm{L}$, alkaline phosphatase $177 \mathrm{U} / \mathrm{L}$, gamma-glutamyltransferase $511 \mathrm{U} / \mathrm{L}$ ). The nasopharyngeal swab PCR was negative for Influenza $\mathrm{A}$ and $\mathrm{B}$, respiratory syncytial virus, and SARS-CoV2. To complete the diagnostic work-up, we performed an RT-PCR for SARS-CoV-2 in a lower tract respira- tory specimen (induced sputum), which was negative. An ultra-low-dose chest CT-scan showed multi-lobular infiltrates, which were suggestive of SARS-CoV2 infection (Figure 1). The clinical and radiological presentation was in favor of infectious exacerbation of COPD, and empiric antibiotic therapy with amoxicillin/clavulanate and azithromycin was started. Nonetheless, we assisted to a progressive decline in respiratory conditions, and the patient deceased on the fourth day of hospitalization. The induced sputum turned finally positive for extensive drug-resistant P. aeruginosa.

\section{Case \#2 - Bilateral pulmonary embolism}

A 48-year-old woman with amyotrophic lateral sclerosis was admitted to the emergency room for worsening dyspnea. The clinical examination showed a sub-febrile $\left(\mathrm{T} 37.5^{\circ} \mathrm{C}\right)$ patient with normal oxygen saturation in room air; the cardiopulmonary examination was unremarkable except for mildly reduced lung sounds in the right lower thorax.

The ECG showed a sinus rhythm at $95 \mathrm{bpm}$ with an s1q 3 pattern; the laboratory exams highlighted a very modest increase in C-reactive protein $(7 \mathrm{mg} / \mathrm{L})$ associated with mild lymphocytopenia $(0.91 \times 10$ E9/L). We performed an ultra-low-dose chest CTscan, which showed bilateral lower lobes infiltrates, with ground-glass areas compatible with interstitial viral pneumonia (Figure 2A). The nasopharyngeal

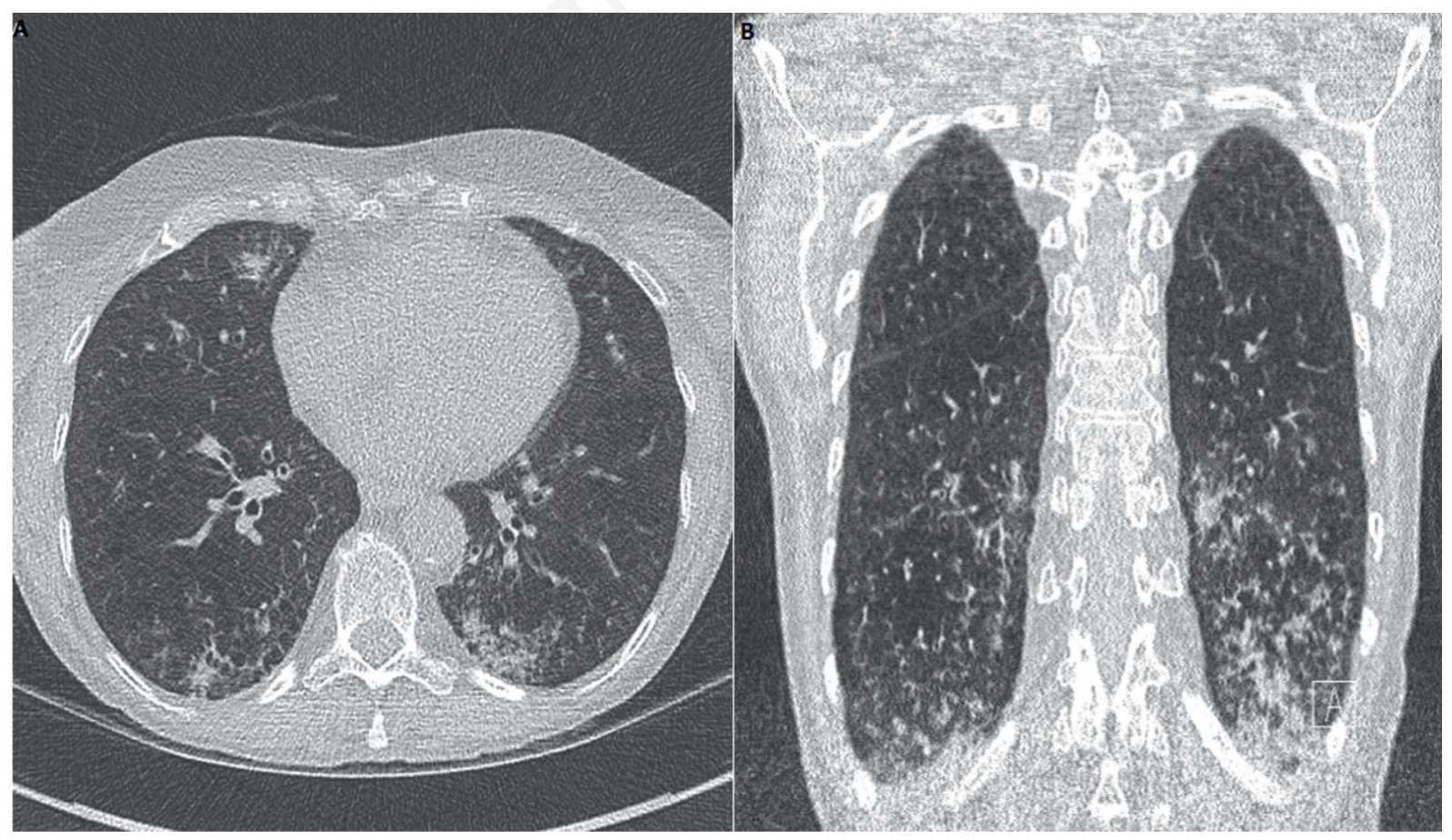

Figure 1. A) Coronary and B) sagittal chest computed tomographic scan showing diffuse bilateral ground-glass opacities and multi-lobular infiltrates. 


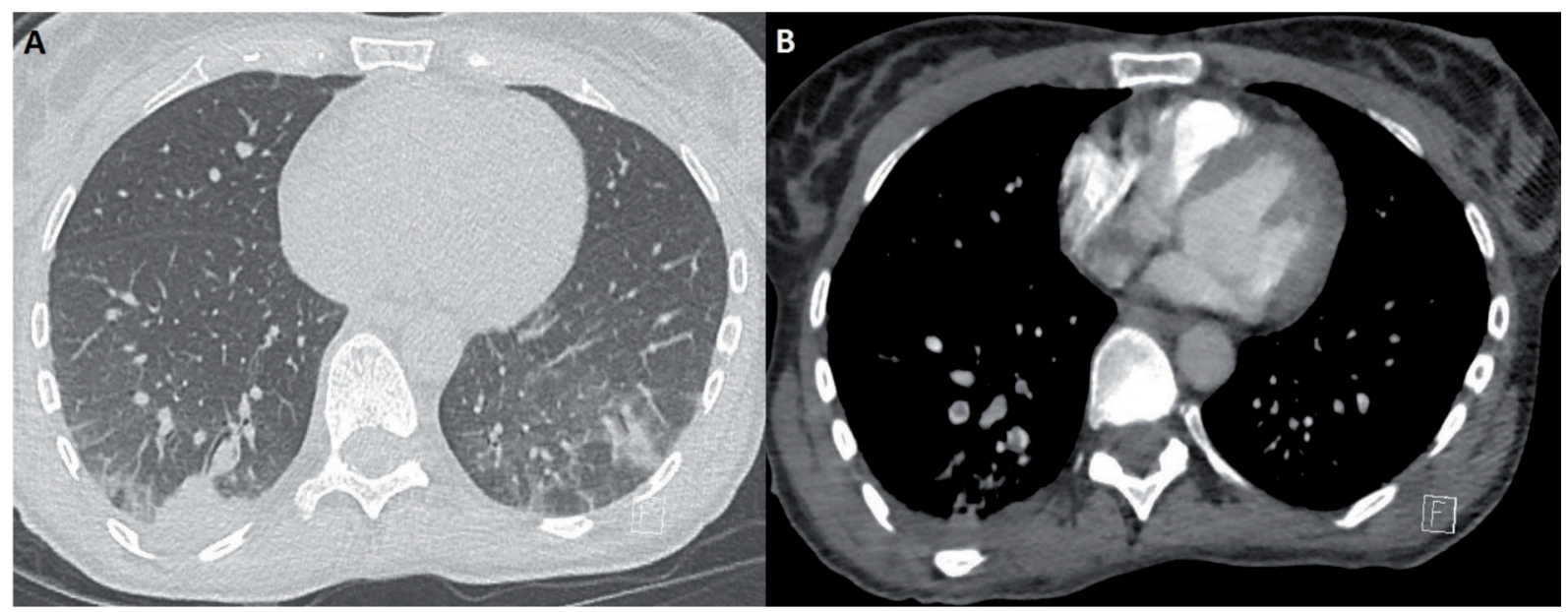

Figure 2. A) Coronary chest computed tomographic (CT) scan showing bilateral lower lobes infiltrates, with groundglass areas compatible with interstitial viral pneumonia and B) angio-CT-scan confirming the presence of multiple pulmonary embolisms, the most remarkable at the right inferior lobe, with associated lung infarction.

swab PCR was negative for influenza A and B, respiratory syncytial virus, and SARS-CoV-2. We completed the diagnostic work-up with a pulmonary angio-CT-scan, which identified the presence of multiple pulmonary embolisms, the most remarkable at the right inferior lobe, with associated lung infarction (Figure 2B). Anticoagulation therapy was started in association with an antibiotic treatment with amoxicillin/clavulanate, the latter to treat a possible bacterial super-infection in the infarcted areas. The patient was discharged home in good general conditions after 5 days.

\section{Discussion and Conclusions}

Prompt recognition, isolation, and rapid treatment initiation in suspected SARS-CoV-2 cases are indispensable during this pandemic. However, the lack of recognition of alternative differential diagnoses and/or co-infections may lead to delay in diagnosis and treatment. Our results highlight the importance of differential diagnosis even in times of widespread occurrence of COVID-19, considering the similarity of symptoms and imaging appearance with other respiratory and systemic conditions.

In our retrospective study, approximately $20 \%$ of hospitalized patients with clinical SARS-CoV-2 suspicion and pathological chest CT-scans had an established alternative diagnosis.

The reported fatality rate due to SARS-CoV-2 infection in Southern Switzerland was 9.4\% and 3.6\% in the world. ${ }^{2}$ In our cohort, the case-fatality rate rises at $10.8 \%$, suggesting that these patients seem to be vulnerable.

Our data suggest that establishing a diagnosis of
SARS-CoV-2 only on clinical and radiological criteria may be a tricky diagnostic strategy. In fact, as mentioned above, one patient out of five with respiratory symptoms and a pathological chest CT-scan will be diagnosed with an alternative condition than COVID19 , such as other infectious and non-infectious diseases. The negativity of RT-PCR for SARS-CoV-2 in nasopharyngeal specimens should prompt further investigation of the presence of SARS-CoV-2 in other specimens, such as induced sputum, feces, and serum while looking for differential diagnoses.

Study limitations are related to the retrospective design and the small sample size. Future studies of decision-making strategies to improve the diagnostic accuracy of SARS-CoV-2 infections are warranted to help clinicians in daily practice.

\section{References}

1. Ufficio Federale della Sanità Pubblica. Press communication; 2020. Available from: https://www.bag.admin.ch/ bag/it/home/das-bag/aktuell/medienmitteilungen.msg-id78233.html Accessed: 23 August 2020.

2. COVID-19 information for Switzerland; 2020. Available from: https://www.corona-data.ch/ Accessed: 23 August 2020.

3. Rigamonti E, Salera D, Gheorghiu AC, Gianella P. The many faces of interstitial pneumonia: a case of presumed SARS-CoV-2 infection. Swiss Med Wkly 2020;150: w20312.

4. MacIntyre CR, Chughtai AA, Barnes M, et al. The role of pneumonia and secondary bacterial infection in fatal and serious outcomes of pandemic influenza a (H1N1). BMC Infect Dis 2018;18:637.

5. Houlihan CF, Patel S, Price DA, et al. A/N1N1 flu pandemic. Life threatening infections labelled swine flu. BMJ 2010;340:c137. 
6. Arashiro T, Nakamura S, Asami T, et al. SARS-CoV-2 and Legionella Co-infection in a person returning from a Nile Cruise. J Travel Med 2020;27:taa053.

7. Li-Ru C, Zheng-Xin C, Yang-Chun L, et al. Pulmonary contusion mimicking COVID-19: a case-report. World J Clin Cases 2020;8:1554-60.

8. Wei-Cai D, Han-Wen Z, Jaun Y, et al. CT imaging and differential diagnosis of COVID-19. Can Assoc Radiol J 2020;71:195-200.

9. Hani C, Trieu NH, Saab I, et al. COVID-19 pneumonia: a review of typical CT findings and differential diagnosis. Diagn Interv Imaging 2020;101:263-8.

10. Bordi L, Nicastri E, Scorzolini L, et al. Differential diagnosis of illness in patients under investigation for the novel coronavirus (SARS-CoV-2) Italy February 2020. Euro Surveill 2020;25:pii=2000170.

11. Colaneri M, Sacchi P, Zuccaro V, et al. Clinical characteristics of coronavirus disease (COVID-19) early findings from a teaching hospital in Pavia, North Italy, 21 to 28 February 2020. Euro Surveill 2020;25:pii=2000460. 